\title{
INFLUENCE OF HABITAT FRAGMENTATION ON SPOTTED OWL SITE SELECTION, SITE OCCUPANCY, AND REPRODUCTIVE STATUS IN WESTERN OREGON
}

\author{
Joseph S. Meyer \\ McKinleyville, CA
}

Larry L. Irwin

National Council for Air and Stream Improvement

Corvallis, OR

\author{
and \\ Mark S. Boyce \\ UW-NPS Research Center \\ Laramie
}

Currently there is little empirical evidence to guide decision makers on how to manage for viable populations of the Northern spotted Owl (strix occidentalis caurina) and how to decide what extent and what types of timber harvesting do not adversely affect spotted Owls. In this ongoing study we are addressing some of the urgent research needs related to Spotted Owls by testing the null hypotheses that various forms of forest fragmentation do not affect (1) site selection, (2) site occupancy, or (3) reproductive success of spotted Owls at sites within the Bureau of Land Management (BL.M) checkerboard pattern of land ownership and management in Western oregon.

our objectives are to (1) estimate several measures of forest fragmentation at known spotted Owl sites, (2) test the null hypothesis of no difference between landscape patterns at randomly-selected owl sites and at randomly selected landscape locations, and (3) test the null hypotheses of zero correlation between forest fragmentation and occupancy or reproduction at spotted Owl sites for which adequate occupancy surveys were conducted for five consecutive years from 1985 to 1989.

Data on occupancy and reproduction at sites in the five BLM Westside Districts were submitted to us by BLM biologists. Based on those lists, we identified 455 sites within the BLM checkerboard pattern of land ownership and management in western oregon that had a pair of owls present at least one year from 1985 to 1989. Eighty of those 455 sites had adequate occupancy surveys conducted in all five years from 1985 to 1989 and did not have birds equipped with radio 
transmitters, whose presence might have affected owl survival or reproduction. We selected 50 of those 80 long-term data sites to test whether forest fragmentation influences site occupancy or reproduction. We also selected 50 sites randomly from the total of 455 sites to test for biases in the sample of 50 long-term data sites. And finally, we selected 50 random landscape locations for comparison with the 50 random owl sites, to test whether forest fragmentation influences site selection by spotted Owls.

The habitat mosaics around each of the 150 sites have been mapped from air photos by the Photogrammetry Branch at the BLM office in Denver, Colorado. From those habitat mosaics, we have calculated several landscape-level characteristics and fragmentation indices for each site. We will also update the habitat mosaics with timber harvesting histories from 1985 to 1989, to account for major habitat changes that may have occurred during the 5-year period. Results for all 150 sites will be combined with the occupancy and reproduction information submitted by BLM biologists, in order to test the three hypotheses stated above.

To date all sites have been mapped for habitat types in the air photo interpretation process, but timber harvesting histories have not yet been gathered to update the habitat mosaics in years for which air photo coverage was not available. We anticipate completion of this project by 1 September 1990. 